\title{
Description of the last instar larva and new contributions to the knowledge of the pupa of Dasyhelea mediomunda Minaya (Diptera, Culicomorpha, Ceratopogonidae)
}

\author{
FLORENTINA DÍAZ ${ }^{1}$, DANIELLE ANJOS-SANTOS ${ }^{2}$, AMPARO FUNES ${ }^{1}$ and MARÍA M. RONDEROS ${ }^{3}$ \\ ${ }^{1}$ UNLP, FCNYM, División Entomología, Museo de La Plata, Paseo del Bosque, s/n, 1900 La Plata, Buenos Aires, Argentina \\ ${ }^{2}$ Universidad Nacional de la Patagonia "San Juan Bosco", Centro de Investigación Esquel de \\ Montaña y Estepa Patagónica - CIEMEP, Laboratorio de Investigaciones en Ecología y Sistemática \\ Animal (LIESA), CONICET - Sarmiento, 849, 9200 Esquel, Chubut, Argentina \\ ${ }^{3}$ Centro de Estudios Parasitológicos y de Vectores (CEPAVE), Facultad de Ciencias Naturales y Museo (UNLP), Consejo \\ Nacional de Investigaciones Científicas y Técnicas/CONICET, Boulevard 120, s/n, e/61 y 62 La Plata, Buenos Aires, Argentina \\ Manuscript received on February 4, 2015; accepted for publication on September 2, 2015
}

\begin{abstract}
The fourth instar larva of Dasyhelea mediomunda Minaya is described for the first time and a complete description of the pupa is provided, through use of phase-contrast microscope and scanning electron microscope. Studied specimens were collected in a pond connected to a small wetland "mallin" on the Patagonian steppe, Chubut province, Argentina.
\end{abstract}

Key words: Argentina, Dasyhelea mediomunda, immature stages, Patagonian steppe.

\section{INTRODUCTION}

Biting midges of the genus Dasyhelea Kieffer are a large and complex group of Ceratopogonidae with diverse morphology and biology, occurring worldwide in a variety of habitats (Waugh and Wirth 1976). Taxonomically, the recognition of the subgenera and/or species groups is still incipient and generally, the subgeneric division has been only sporadically applied to various regional faunas (Díaz et al. 2014). At present there are 70 extant species of Dasyhelea inhabiting the Neotropical region (Borkent 2015), of which 12 belong to the cincta species-group as defined by Waugh and Wirth (1976) and, of this number, three occur in Patagonia. Regarding the immatures of this group, only four species are known: D. bahamensis (John-

Correspondence to: Florentina Díaz

E-mail: mfdiaz@fcnym.unlp.edu.ar son) (Ronderos et al. 2003), D. cincta (Coquillett) (Spinelli 1983, Díaz et al. 2009), D. mediomunda Minaya (Minaya 1978) and D. paracincta Wirth (Borkent 1991). The original descriptions of the pupa of D. mediomunda by Minaya (1978) and the one given by Spinelli and Wirth (1984) in the revision of Dasyhelea cincta species group from the Neotropical region are very incomplete.

During a recent entomological survey carried out in the vicinity of Esquel, Chubut, immatures of Dasyhelea cincta species group were collected.

The purpose of this paper is to provide the first description of the last instar larva and a full description of the pupa of D. mediomunda.

\section{MATERIALS AND METHODS}

Larvae and pupae of $D$. mediomunda were collected with a pipette from a pond connected to a 
wetland "mallin". Specimens were carried to the laboratory, larvae were placed individually in plastic containers with water from the same pond and pupae were isolated in a vial with a drop of water and observed daily until adult emergence. Adults were allowed to harden for 24 hours before being preserved to ensure their pigmentation was complete. Immatures and adults were mounted in Canada balsam following the technique described by Borkent and Spinelli (2007).

For Scanning Electron Microscope (SEM), larvae were prepared following the technique of Ronderos et al. (2000, 2008). Ink illustrations were made using a Camera lucida attached to a Nikon Eclipse E200 microscope and photographs were taken with a digital camera Micrometrics SE Premium, through the same microscope. Measurements were taken using Compound Microscope (CM).

For larval terminology see Díaz et al. (2013) and for pupal terminology see Borkent (2014).

\section{RESULTS}

\section{Dasyhelea mediomunda Minaya, 1978}

(Figs. 1-4)

Dasyhelea mediomunda Minaya 1978: 79 (male, female, pupa, Peru); Spinelli and Wirth 1984: 604 (revision, cincta group; record from Chile); Borkent and Wirth 1997: 56 (World catalogue); Borkent and Spinelli 2000: 25 (catalogue south of USA); Borkent and Spinelli 2007: 60 (Neotropical catalogue); Díaz et al. 2009: 154 (revision, cincta group from Patagonia; record from Argentina); Spinelli and Marino 2009: 209 (list of species of Patagonia); Spinelli and Ronderos 2011: 123 (list of species of the Nahuel Huapi National Park, Argentina); Borkent 2015: 67 (in online World catalogue). Material examined. ARGENTINA: CHUBUT: Provincial Road 12, "El Tropezón", 4247’44.2”S; 7051'07.7'W, $781 \mathrm{~m}, 13 . x i 1.2012$, Anjos-Santos,
D. leg., $1 \hat{\jmath}$ (with larval and pupal exuvium), 2 ㅇ (with larval and pupal exuviae), $1 \hat{\delta}$ (with pupal exuvium), 2 o pupal exuviae, 3 pupal exuviae, $1 \delta$ pupal exuviae (with larval exuviae), 2 larvae exuviae.

Specimens examined by SEM. Same data, 1 larva, 2 pupae.

Description fourth instar larva (Figs. 1a-e, 3ae). Head capsule pale brown, short, wide, tapering to apex (Figs. 1a-b); chaetotaxy as in Figs. $1 \mathrm{a}-\mathrm{b}$; HL 0.45-0.52 (0.48, n=4) mm; HW 0.37-0.45 $(0.41, \mathrm{n}=4) \mathrm{mm}$; HR 1.03-1.31 (1.16, n=4); SGW $0.025-0.27(0.255, \mathrm{n}=4) \mathrm{mm}$; SGR 1.48-1.60 $(1.63, \mathrm{n}=4)$. Antennae short. Labrum twice as wide as long (Figs. 1a-b); anterior portion of palatum (Fig. 1a) with 3 pairs of campaniformia (Figs. 1b, d), posterior portion with 2 pairs of sensilla coeloconica, mesal one serrate (Figs. 1b, d); messors (Figs. 1d, 3a, d) well developed, curved, appearing to be two segmented; scopae inconspicuous. Mandible (Fig. 3a) stout, heavily sclerotized, with 2 teeth, apical one longer than proximal tooth; MDL 0.09-0.12 $(0.11, \mathrm{n}=4) \mathrm{mm}$. Maxilla (Fig. 1c) heavily sclerotized; galeolacinia (Fig. 1b) with long, thin seta and flap-like lobe; maxillary palpus (Figs. 1b-d) short, button-like, with 2-4 small papillae. Hypostoma (Figs. 1a-b, d) with medial portion smooth, flanked with 4 strong, lanceolate teeth followed by 3 small teeth on each side. Epipharynx (Figs. 3b-c) massive, heavily sclerotized, with middle size, strong teeth on the median sclerite, and stout lateral arms lacking teeth; LAW 0.22-0.225 (0.223, $\mathrm{n}=2) \mathrm{mm}$, DCW 0.095-0.15 (0.123, n=2) mm. Hypopharynx (Figs. $3 \mathrm{~b}, \mathrm{c})$ stout, heavily sclerotized, posterior comb straight with fringe, labium short not surpassing the hypostoma. Thoracic pigmentation hyaline. Abdominal segments whitish, with diffuse pale brown pigmentation. Caudal segment (Figs. 1e, $3 \mathrm{e})$ with anterior ring of short spines and 5 pairs of short, stout, brown pointed hooks and one pair of 
seta "o" and "i". CSL 0.21-0.45 (0.33, n=3) mm, CSW 0.25-0.40 (0.33, n=3) mm, CSR 0.76-0.87 $(0.81, \mathrm{n}=2) \mathrm{mm}$.

Redescription female pupa (Figs. 2a-i, 3f-h, 4a-c). General coloration of exuvium pale brown, except anterior portion of cephalotorax brown. Total length 3.80-4.08 (3.95, n=5) mm. Exuvium with flagellum appressed against lateral margin of face. Dorsal apotome (Figs. 2b-d, 3g) $2.66 \mathrm{X}$ broader than long, apex rounded, surface covered with small rounded tubercles, anterior margin slightly concave with a notch, with 2 pairs of raised, wrinkled areas;
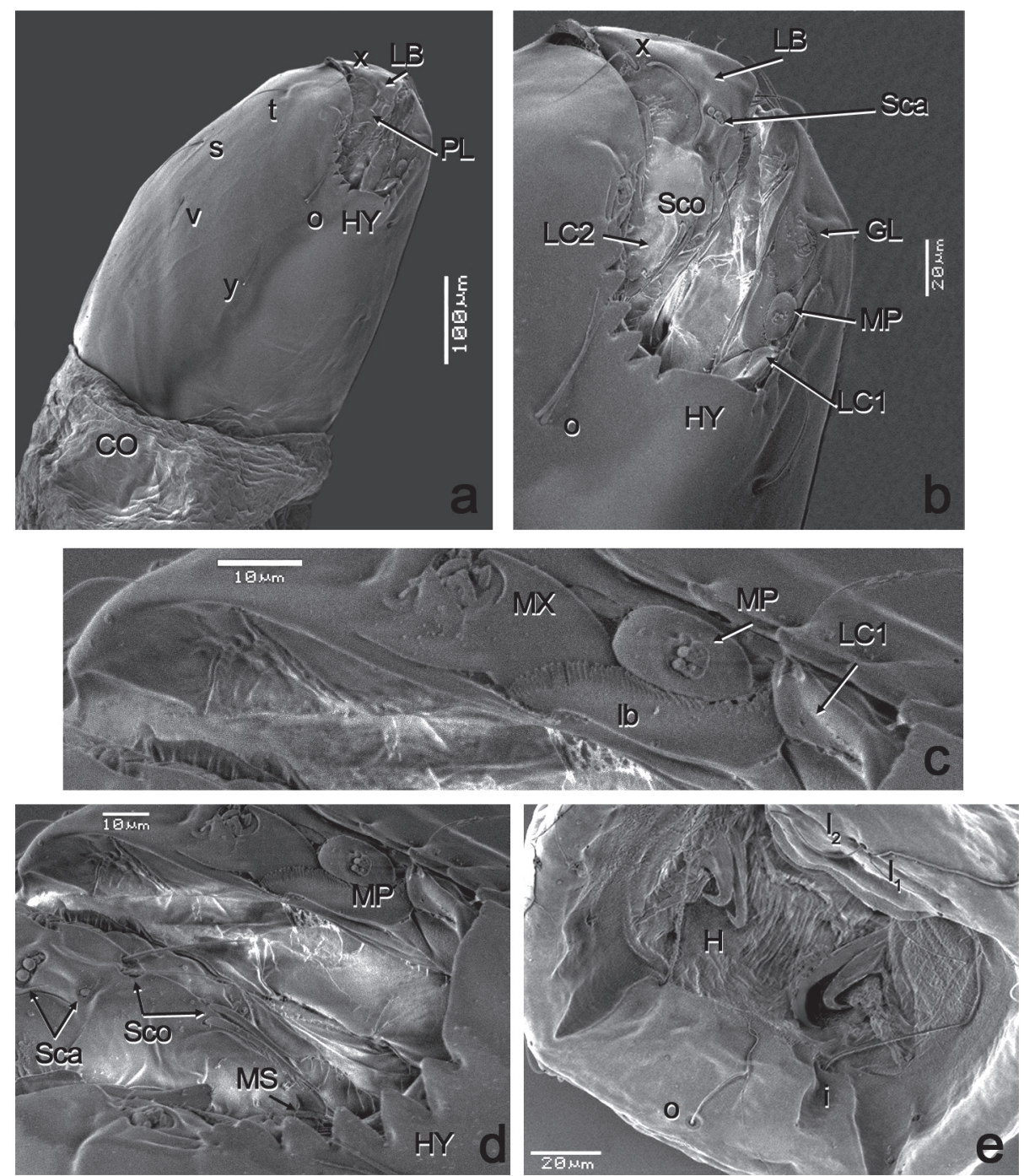

Figure 1a-e - Dasyhelea mediomunda Minaya, larva (SEM). a, head capsule (chaetotaxy, lateroventral view); b, head capsule (details, lateroventral view); c, details of mouthparts (ventral view); d, mouthparts (ventral view); e, caudal segment. Collar (CO); galeolacinia (GL); hypostoma (HY); hooks (H); labrum (LB); lacinial sclerite 1 (LC1); lacinial sclerite 2 (LC2); maxilla (MX); maxillary palpus (MP); messors (MS); palatum (PL); sensilla coeloconica (Sco); sensilla campaniformia (Sca). Head capsule chaetotaxy: o, parahypostomal setae; s, anterior perifrontal setae; $t$, prefrontal setae; v, posterolateral setae; $x$, parantennal setae; $y$, ventral setae. Caudal segment chaetotaxy: o, outer setae; $i$, inner setae; $1_{1}$ first lateral setae; $1_{2}$, second lateral setae. 
dorsal apotome sensilla (Figs. 2b-d, 3g) DA-1-H long, thin seta, DA-2-H campaniform sensillum; posterior margin rounded with stout, dorsomedial, rounded tubercle; DAL $0.10 \mathrm{~mm}$; DAW $0.38 \mathrm{~mm}$;
DAW/DAL 3.80; mouthparts with mandible, lacinia absent; palpus extending posterior to posterolateral margin of labium; labium divided medially by longitudinal suture. Cephalothorax (Fig. 2a)
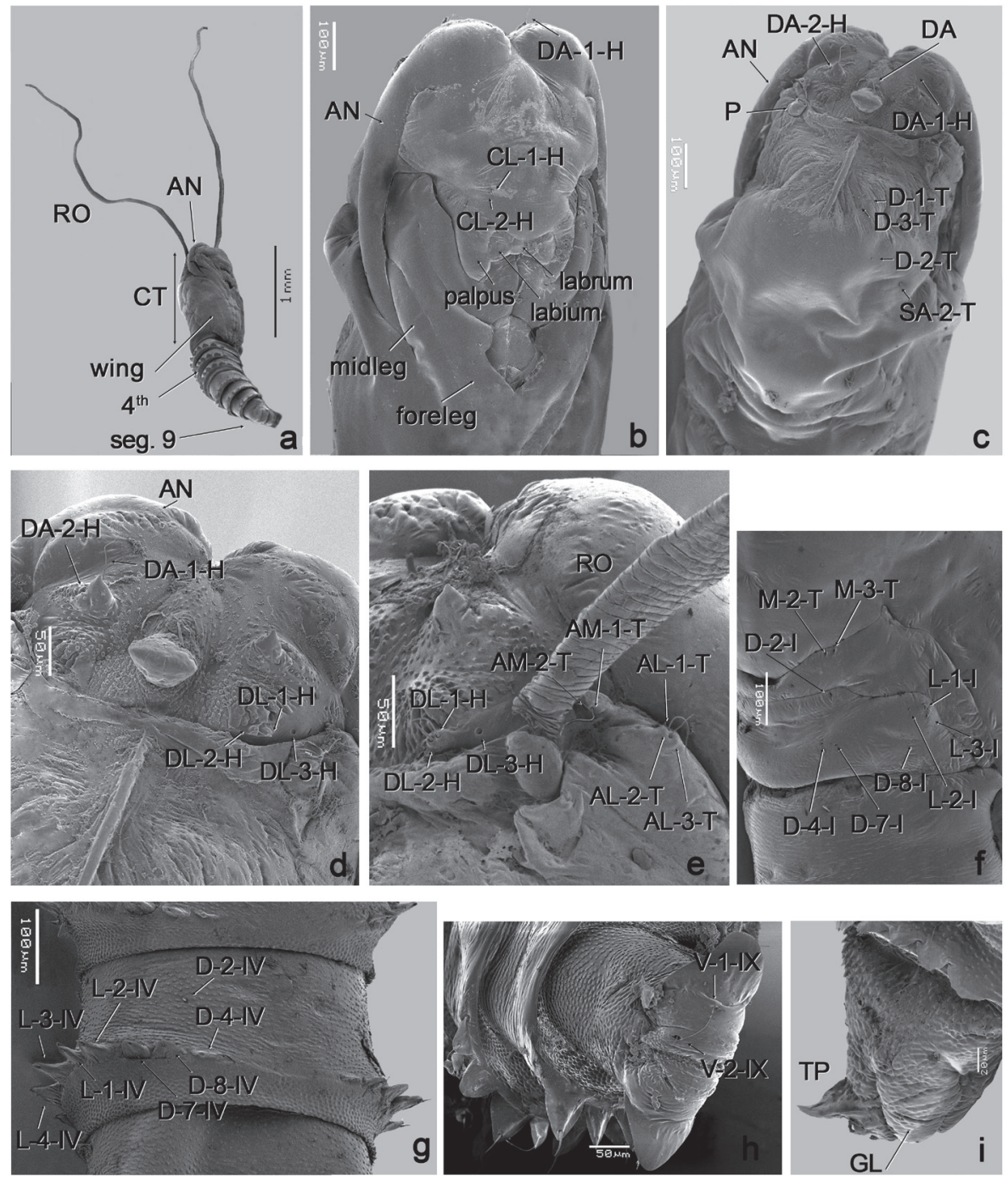

Figure 2a-i - Dasyhelea mediomunda Minaya, pupa (SEM). a-h female pupa, i male pupa; a, entire pupa (lateroventral view); b, cephalothorax (ventral view); c, cephalotorax (dorsal view); d, dorsal apotome (chaetotaxy); e, cephalotoracic sensilla and respiratory organ; $\mathbf{f}$, metathoracic and first abdominal segment (chaetotaxy); g, chatotaxy of segment 4 of abdomen; h-i, segment 9. Antenna (AN); anterolateral sensilla (AL-1-T, AL-2-T, AL-3-T); anteromedial sensilla (AM1-T, AM-2-T); cephalothorax (CT); clypeal/labral sensilla (CL-1-H, CL-2-H); dorsal apotome (DA); dorsal apotome sensilla (DA-1-H, DA-2-H); dorsolateral cephalic sclerite sensilla (DL1-H, DL-2-H, DL-3-H); dorsal sensilla of first abdominal segment (D-2-I, D-4-I, D-7-I, D-8-I); dorsal sensilla of segment 4 (D-2-IV, D-4-IV, D- 7-IV, D-8-IV); dorsal setae (D-1-T, D-2-T, D-3-T); genital lobe (GL); lateral sensilla of first abdominal segment (L-1-I, L-2-I, L-3-I); lateral sensilla of segment 4 (L-1-IV, L-2-IV, L-3-IV, L-4-IV); methatoracic sensilla (M-2-T, $\mathrm{M}-3-\mathrm{T})$; pedicel (P); respiratory organ (RO); supraalar sensillum (SA-2-T); terminal processes (TP); ventral sensilla of ninth abdominal segment (V-1-IX, V-2-IX). 

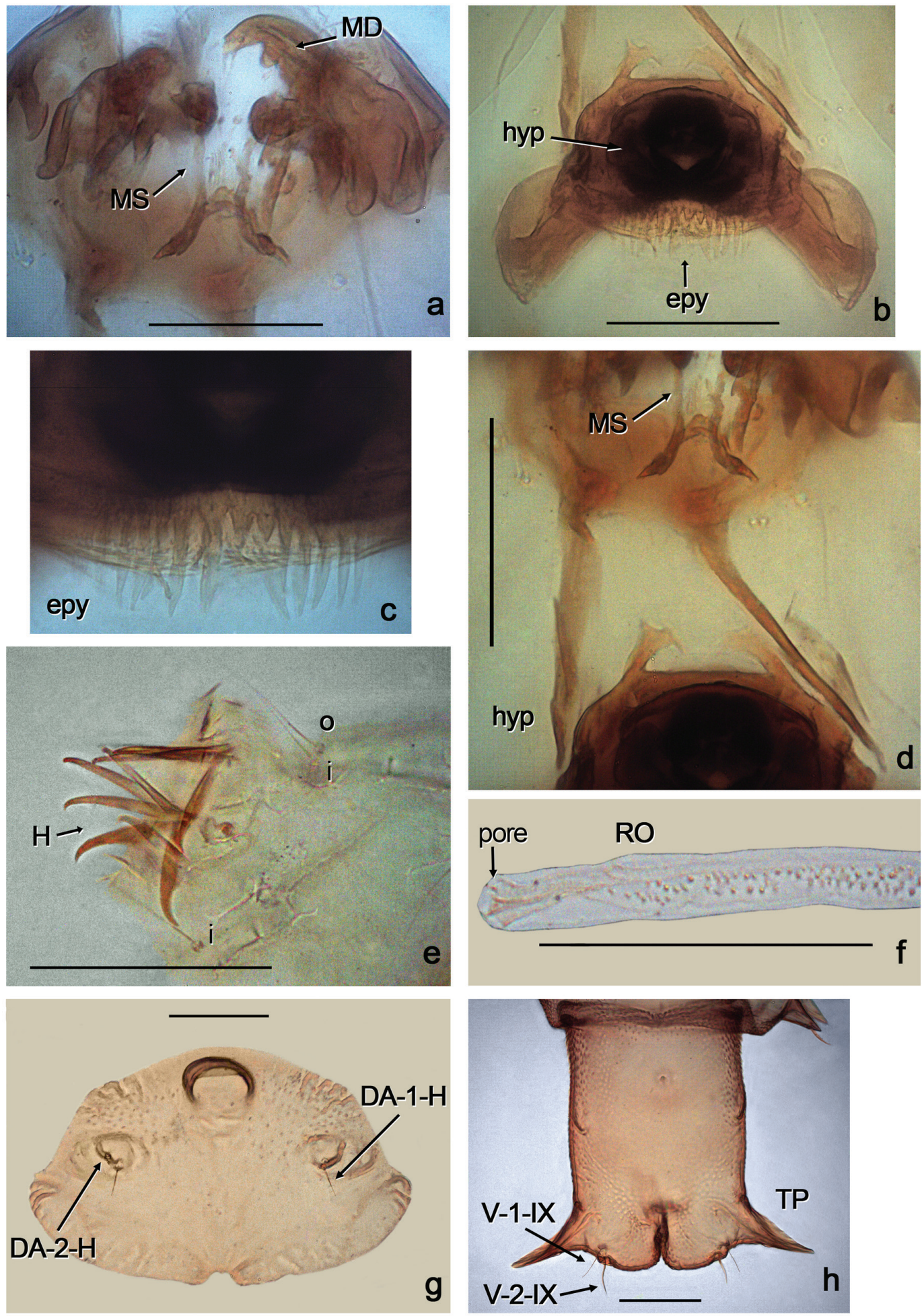

Figure 3a-h - Dasyhelea mediomunda Minaya, a-e larva, f male pupa, g-h female pupa; a, mandible and messors; b, epipharynx and hypopharynx; c, epypharynx; d, hypopharynx and messors; e, caudal segment; f, respiratory organ; g, dorsal apotome; h, segment 9. Dorsal apotome sensilla (DA-1-H, DA-2-H); epypharynx (epy); hypopharynx (hyp); hook (H); inner setae (i); mandible (MD); messors (MS); outer setae (o) respiratory organ (RO); terminal processes (TP); ventral sensilla of ninth abdominal segment (V-1-IX, V-2-IX). 
surface with small rounded tubercles, length 1.40 $1.77(1.60, \mathrm{n}=5) \mathrm{mm}$, width 0.775-0.925 (0.862, $\mathrm{n}=5) \mathrm{mm}$. Cephalothoracic sensilla as follows: three dorsolateral cephalic sclerite sensilla (Figs. 2d-e) DL-1-H medium-sized, thin seta, DL-2-H stout, short setae, DL-3-H campaniform sensillum; three anterolateral sensilla (Fig. 2e), AL-1-T long, thin seta, AL-2-T medium-sized, thin, AL3-T short, stout setae; two anteromedial sensilla (Fig. 2e), AM-1-T long, thin seta, AM-2-T short, thin seta; two clypeal/labrals (Figs. 2b, 4a); CL1-H medium-sized, thin seta, CL-2-H short seta; two ocular sensilla, O-1-H long, thin, seta, O-2-H campaniform sensillum (Fig. 4a). Respiratory
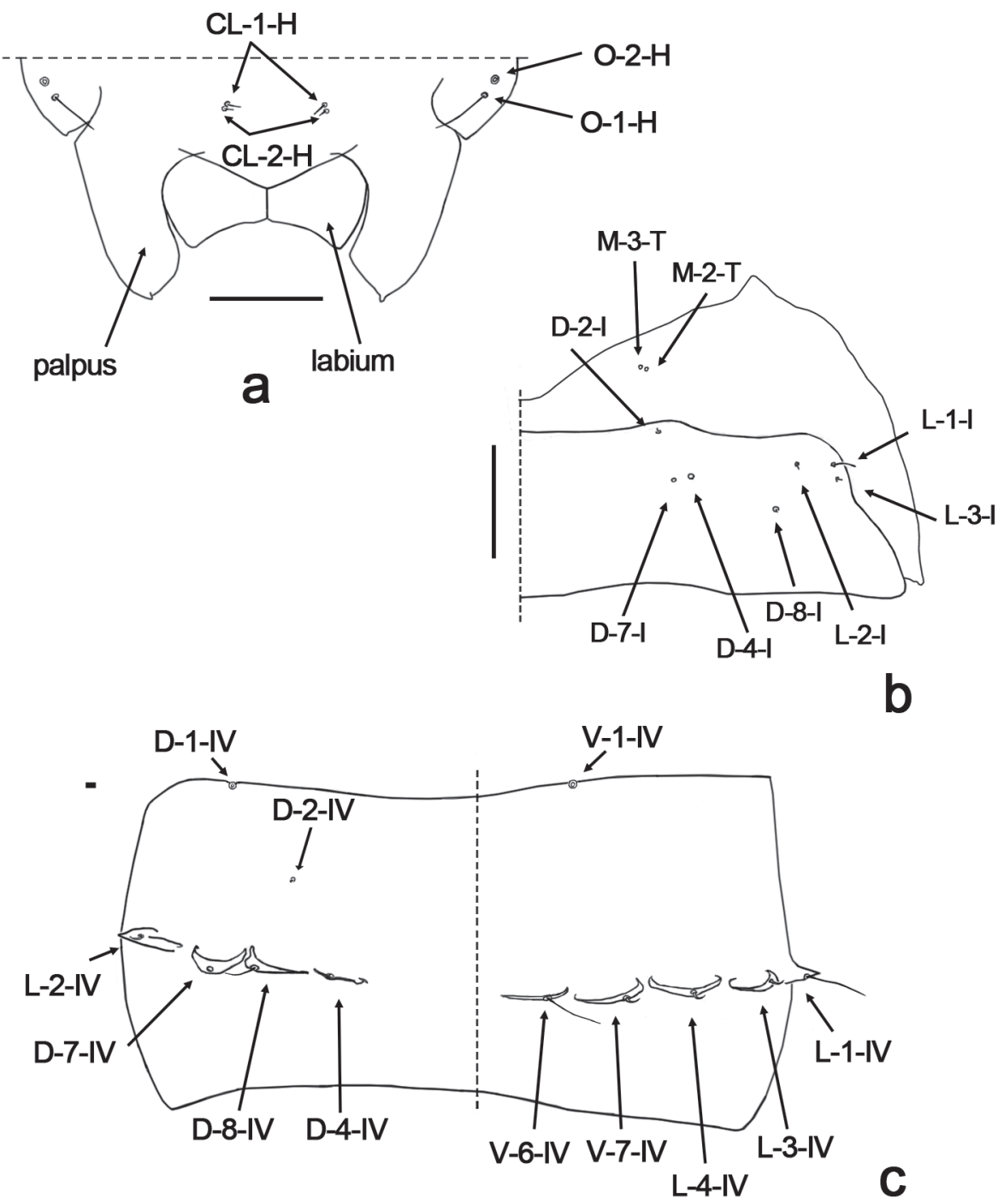

Figure 4a-c - Dasyhelea mediomunda Minaya, female pupa, a, clypeal/ labral and ocular sensilla (details, ventral view); b - metathoracics and first abdominal segment chaetotaxy; c - fourth abdominal segment chaetotaxy. Clypeal/labrals sensilla (CL-1-H, CL-2-H); dorsal sensilla of first abdominal segment (D-2-I, D-4-I, D-7-I, D-8-I); dorsal sensilla of segment 4 (D-1-IV, D-2-IV, D-4-IV, D- 7-IV, D-8-IV); lateral sensilla of first abdominal segment (L-1-I, L-2-I, L-3-I); lateral sensilla of segment 4 (L-1-IV, L-2-IV, L-3-IV, L-4-IV); methatoracic sensilla (M-2-T, M-3-T); ocular sensilla (O-1-H, 0-2-H); ventral sensilla of segment 4 (V-1-IV, V-6-IV, V-7-IV). 
organ (Figs. 2a, e) brown, slender, as long as total length of pupa, annulated on entire extension, with 3-4 apical and 22-24 lateral pores; RO length 3.20-3.75 (3.34, n=4) mm, RO width 0.03-0.06 $(0.04, \mathrm{n}=4) \mathrm{mm}$; without pedicel. Dorsals (Fig. 2c): D-1-T short, thin seta, D-3-T campaniform sensillum, D-2-T minute setae, supraalar (SA2-T) campaniform sensillum. Metathoracics (Figs. 2f, 4b): M-2-T-M-3-T campaniform sensilla. Abdominal segments covered with small spinules. First abdominal segment (Figs. 2f, 4b) with sensilla as follows: D-2-I peg; D-4-I, D-7-I campaniform sensilla, D-8-I minute seta; L-1-I long thin seta, L-2-I, L-3-I short, thin setae. Second abdominal segment similar to the first one. Segment 4 with sensillar pattern (Fig. 2g) as follows: D-2-IVshort seta; D-4-IV, D-7-IV campaniform sensilla, D-8IV medium-sized, thin seta, all located on flattened tubercles; L-1-IV medium-sized, thin seta, L-2IV, L-3-IV-L-4-IV short, thin setae, all located on triangular tubercles; V-5-IV long, thin seta, V-6-IV short, stout seta, both on flattened tubercles.

Segment 9 (Figs. 2h, 3h)1.50 X longer than wide, ventral surface with many spinules; length 0.30 $0.35(0.31, \mathrm{n}=5) \mathrm{mm}$, width $0.20-0.29(0.24, \mathrm{n}=5)$ $\mathrm{mm}$. Terminal process (Figs. 2h, 3h) triangular, divergent, tip pointed, base wide two setae, one long, thin seta on small rounded base, other medium-sized, stout seta on rounded tubercle; length $0.10-0.12(0.11 \mathrm{n}=5) \mathrm{mm}$.

Male pupa. Similar to female with usual sexual differences. Total length 3.51-4.27 (4.00, $\mathrm{n}=3) \mathrm{mm}$. Exuvium pale brown, except cephalotorax brown. Dorsal apotome with DAL $0.105 \mathrm{~mm}$; DAW $0.335 \mathrm{~mm}$, DAW/DAL 3.38. Respiratory organ (Fig. 3f), RO length 3.15-3.90 (3.53, n=4) mm, RO width 0.02-0.05 (0.03, n=4); without pedicel. Cephalotorax: length 1.57-1.80 (1.73, $\mathrm{n}=4) \mathrm{mm}$, width 0.92-0.97 (0.94, n=4) mm. Segment 4 as in Fig. 4c. Segment 9 (Fig. 2i) length 0-34-0.37 $(0.35, \mathrm{n}=4) \mathrm{mm}$, width $0.22-0.29(0.25, \mathrm{n}=4) \mathrm{mm}$; terminal process length $0.08-0.16(0.11, \mathrm{n}=4) \mathrm{mm}$.
Distribution: Peru (Lima), Chile (Valparaíso, Nuble), Argentina (Neuquén, Río Negro and Chubut).

\section{DISCUSSION}

The larva of Dasyhelea mediomunda is very similar to that of D. bahamensis by virtue of the short head capsule, the hypostoma bearing the medial portion smooth, the maxillary palpus short and button-like, the lateral arms of epipharynx stout and lacking teeth, and the caudal segment lacking hooklets. However, the larva of D. bahamensis differs by having the palatum with one pair of sensilla campaniformia, the scopae absent; the mandible with three teeth, and the hypostoma having fivesix teeth. The pupa is very similar to those of $D$. bahamensis and D. cincta slender and annulated respiratory organ, which is twice as long as the total length of pupa. The pupae of $D$. bahamensis and $D$. cincta differ by the number of pores of the respiratory organ (D. bahamensis has 6 apical and 17 lateral pores and D. cincta bears 8-9 and 14-16, respectively).

Finally, the immatures of $D$. mediomunda could be also compared with $D$. paracincta. In the original description, Borkent (1991) mentioned only the head capsule length of the larva and the coloration and number of pores of the respiratory organ of the pupa (pale yellow with apex darkly pigmented, and 11-13 apical and 12-18 lateral pores respectively).

Ronderos et al. (2003) in the original description of the larva and pupa of D. bahamensis, incorrectly mentioned 5 dorsoposteromarginal setae (d.p.m.) and 4 ventroposteromarginal setae (v.p.m.). Díaz et al. (2009) in the redescription of pupa of D. cincta also incorrectly mentioned 4 d.p.m. and 3 v.p.m.

A detailed revision of the pupae of $D$. bahamensis and D. cincta during the present study revealed that the d.p.m. (currently named D-IV) and v.p.m (currently named V-IV) are represented by 3 and 2 setae respectively, and the respiratory organ of both species lacks pedicel. 


\section{BIONOMICS}

Immatures of Dasyhelea mediomunda were collected together with Culicoides lacustris Ronderos in a pond connected to a wetland ("mallin"), fed by groundwater, with intermittent flooding regime, without fishes in the semi-arid Patagonian Steppe (Epele and Archangelsky 2012). Larvae and pupae were collected in December on a sunny day, between 2:00-2:30 pm, air temperature was $20^{\circ} \mathrm{C}$, water temperature was $17^{\circ} \mathrm{C}, \mathrm{pH} 7.5$. In the laboratory, with a temperature of $18-21{ }^{\circ} \mathrm{C}$, two larvae lasted five days to reach to pupal stage. Pupae completed their development in seven days. Larvae were motionless or only exhibited slow movements; pupae exhibited circular, slow abdominal movements.

\section{ACKNOWLEDGMENTS}

We are grateful to Nélida Caligaris for technical assistance, to Dr. Pablo Pessacq for help in the collection and rearing in the laboratory, and to Dr. Miguel Archangelsky for critical reading of the manuscript. This work was supported by National Research Council of Argentina (CONICET, Argentina). This is contribution number 108 of the LIESA.

\section{RESUMO}

A larva de quarto ínstar de Dasyhelea mediomunda Minaya é descrita pela primeira vez e a descrição completa da pupa é fornecida, através da utilização de microscópio de contraste de fases e microscopia eletrônica de varredura. Os espécimes estudados foram coletados em um "mallin" conectado à zonas úmidas na estepa patagônia, Província de Chubut, Argentina.

Palavras-chave: Argentina, Dasyhelea mediomunda, estágios imaturos, estepa patagônia.

\section{REFERENCES}

BorkenT A. 1991. The Ceratopogonidae Diptera of the Galapagos islands ecuador with a discussion of their phylogenetic relationships and zoogeographic origins. Entomol Scand 22: 97-122.
BORKENT A. 2014. The pupae of the Biting Midges of the world (Diptera: Ceratopogonidae), with a generic key and analysis of the phylogenetic relationships between Genera. Zootaxa 3879: 1-327.

BORKENT A. 2015. World species of biting midges (Diptera: Ceratopogonidae). Last update February 9, 2015. http:// www.inhs.uiuc.edu/research/FLYTREE/CeratopogonidaeCatalog.pdf, 236 p.

BORKENT A AND SPINELli GR. 2000. Catalog of the New World biting midges south of the United States of America (Diptera: Ceratopogonidae). Contrib Entomol Internat 4: $1-107$.

BORKENT A AND SPINELLI GR. 2007. Neotropical Ceratopogonidae (Diptera: Insecta). In: Adis J et al. (Eds), Aquatic Biodiversity in Latin America (ABLA). Vol. 4. Pensoft, Sofia-Moscow, $198 \mathrm{p}$.

BORKENT A AND WIRTH WW. 1997. World species of biting midges (Diptera: Ceratopogonidae). Bull Am Mus Nat Hist 233: 1-257.

DÍAZ F, RONDEROS MM, SPINELLI GR, FERREIRA-KEPPLER RL AND TORREIRAS SRS. 2013. A new species of Dasyhelea Kieffer (Diptera: Ceratopogonidae) from Brazilian Amazonia. Zootaxa 3686: 85-93.

DÍAZ F, SPINELli GR AND Ronderos MM. 2009. Biting Midges of the Dasyhelea cincta group from Patagonia (Diptera, Ceratopogonidae). Dtsch entomol Z 56: 149-156.

DÍAZ F, TORREIRAS SRS, SPINELLI GR AND RONDEROS MM. 2014. A new species of Dasyhelea from Brazilian Amazonas and the description of the male of D. paulistana (Diptera: Ceratopogonidae). Acta Entomol Mus Nat Pragae 54: 715-728.

EPELE LB AND ARCHANGELSKY M. 2012. Spatial Variations in Water Beetle Communities in Arid and Semi-Arid Patagonian Wetlands and Their Value as Environmental Indicators. Zool Stud 51: 1418-1431.

MiNAYA G. 1978. Dasyhelea mediomunda, sp. n. (Diptera: Ceratopogonidae) de la costa central del Perú. Rev Peru Entomol 21: 79-81.

RondERos MM, DÍAZ F AND SARMIENTO P. 2008. A new method using acid to clean and a technique for preparation of eggs of biting midges (Diptera: Ceratopogonidae) for Scanning Electron Microscope. Trans Am Entomol Soc 134: 471-476.

RONDEROS MM, SPINELli GR, HUERTA H AND DÍAZ F. 2003. Inmature stages of two Neotropical species of Dasyhelea Kieffer, 1911. (Diptera: Ceratopogonidae). Trans Am Entomol Soc 129: 295-308.

RONDEROS MM, SPINELLI GR AND SARMIENTO P. 2000. Preparation and Mounting of Biting Midges of the Genus Culicoides Latreille (Diptera: Ceratopogonidae) to be observed with a Scanning Electron Microscope. Trans Am Entomol Soc 126: 125-132.

SPINELLI GR. 1983. Notas sobre Ceratopogonidae (Diptera, Nematocera) de la República Argentina. Una nueva especies del género Alluaudomyia Kieffer, redescripción 
de Dasyhelea penthesileae Macfie, y nuevas citas para el género Stilobezzia Kieffer. Limnobios 2: 403-411.

SPINELLI GR AND MARINO PI. 2009. Estado actual del conocimiento de la familia Ceratopogonidae en la Patagonia (Diptera: Nematocera). Rev Soc Entomol Argent 68: 201-208.

SPINELli GR AND RONDEROS MM. 2011. Orden Diptera. Familia Ceratopogonidae. En: Massaferro J (Comp.). Guía de Insectos Acuáticos del Parque Nacional Nahuel Huapi.
Larvas y Pupas. $1^{\text {er }}$ ed., Río Negro Administración de Parques Nacionales, 2011 Fundación Flores, p. 118-127.

SPINELLI GR AND WIRTH WW. 1984. Las especies Neotropicales del género Dasyhelea, grupo cincta (Diptera: Ceratopogonidae). Limnobios 2: 586-608.

WAUGH WT AND WIRTH WW. 1976. A revision of the genus Dasyhelea Kieffer of the eastern United States north of Florida (Diptera: Ceratopogonidae). Ann Entomol Soc Am 69: 219-247. 